\title{
DILEMAS DA AÇÃO COLETIVA: UM OLHAR SOCIOLÓGICO PARA AS TENSÕES DA EXPERIÊNCIA
}

\author{
$*$ \\ Matheus Mazzilli Pereira \\ Universidade Federal do Rio Grande do Sul - UFRGS - Brasil \\ Thales Speroni Pereira da Cruz \\ Universidade Federal do Rio Grande do Sul - UFRGS - Brasil \\ Universidade Autônoma de Barcelona - UAB - Espanha
}

\begin{abstract}
Resumo
O campo de estudos da ação coletiva, sobretudo, ao longo das décadas de 1970 e 1980, foi marcado por intensas disputas entre, por um lado, abordagens que enfatizavam a ação "instrumental" dos movimentos sociais em busca pelos recursos escassos controlados pelo Estado e, por outro lado, perspectivas que enfatizavam a ação "ideológica" desses atores em sua busca pela criação de novas percepções culturais que fomentassem sua autonomia frente às demandas do mercado e da tradição. Desde então, podem ser observados esforços de síntese que procuram vincular essas dimensões da ação coletiva. Essas novas perspectivas se caracterizam pela desconstrução de dicotomias e pela afirmação de que diferentes tipos de racionalidades e motivações estão sempre presentes na ação social, destacando que as interações entre Estado e movimentos sociais não implicam, necessariamente, uma perda de autonomia dos atores coletivos contestatórios. No âmbito deste artigo, postula-se que, se esse projeto sintético permite um afastamento em relação às premissas normativas sobre "o que é a política", é necessário que o arsenal conceitual disponibilizado possibilite a compreensão de que essa é uma questão que está, cotidianamente, em disputa entre atores coletivos contestatórios. Defende-se que a contribuição teórica de François Dubet fornece fundamentos contundentes para a construção de um modelo apropriado para essa tarefa. A partir dessas reflexões, é proposto um deslocamento na abordagem sociológica da ação coletiva, abandonando a tarefa de resolução teórica dos dilemas que são, de fato, empíricos, em direção a uma postura compreensiva sobre o modo como essas tensões são resolvidas pelos atores efetivamente envolvidos em ações coletivas contestatórias.
\end{abstract}

Palavras-chave: dilemas; movimentos sociais; lógicas de ação. 


\section{Introdução ${ }^{1}$}

As teorias da ação coletiva construídas ao longo das décadas de 1960 e 1970 deram origem a um longo debate teórico sobre a definição do conceito de "movimentos sociais". Discute-se, tanto no sentido conceitual quanto no sentido normativo, que natureza a ação de um ator coletivo contestatório deve ter para que ele possa ser considerado um movimento social. Emergem, assim, disputas teóricas e dilemas sociológicos sobre o tema. Recentemente, diversos estudiosos têm se esforçado para construir sínteses que combinem contribuições de distintas tradições teóricas. Esse projeto sintético, no entanto, corre o risco de, ao superar teoricamente os dilemas, obstaculizar a análise dos dilemas empiricamente vivenciados por atores coletivos contestatórios reais. Este artigo busca revisar esse debate, propondo uma alternativa que, ao mesmo tempo, supere dicotomias conceituais e esteja atenta para as tensões da ação social.

Dessa forma, propõe-se a seguinte pergunta: de quem são os dilemas da ação coletiva? Primeiramente se apresentam abordagens que tratam os dilemas da ação coletiva como sociológicos e, portanto, propõem "soluções sociológicas" para tais. Posteriormente, descreve-se uma tentativa de síntese entre os caminhos apresentados na primeira parte. Por fim, apresenta-se a sociologia da experiência, como uma proposta que permite um deslocamento da análise sociológica em direção a uma virada compreensiva, marcada pelo postulado de que os dilemas da ação coletiva são de posse de atores concretos, restando à sociologia compreender como estes constroem e lidam com tais dilemas, e identificar quais são os elementos contingenciais atuantes nesse processo.

\section{1 - Dilemas Sociológicos: Entre a identidade e a estratégia}

A busca pela superação das teorias clássicas sobre a ação coletiva baseadas em perspectivas marxistas ou funcionalistas deu origem, a partir das décadas de 1960 e 1970, a duas tradições teóricas que contrastavam em seus pressupostos analítico-descritivos ("o que são os movimentos sociais”) e normativos (“o que eles devem ser”). Largamente explorada pela literatura sobre o tema, essa cisão se deu, sobretudo, entre perspectivas europeias e norteamericanas da ação coletiva. Segundo Cohen (1985), essa divergência é caracterizada como uma divisão entre, por um lado, a ação coletiva estrategicamente coordenada para a

\footnotetext{
${ }^{1}$ Uma versão preliminar desse artigo foi apresentada no IV Encontro Internacional de Ciências Sociais, realizado na cidade de Pelotas (Rio Grande do Sul), no ano de 2014.
} 
satisfação de interesses de grupos marginalizados e, por outro lado, a ação coletiva ideologicamente orientada em busca da construção de novas identidades e consensos (Alonso, 2009; Cohen, 1985). Para os propósitos deste trabalho, duas diferenças entre essas perspectivas são ressaltadas: as formas pelas quais cada abordagem concebe a relação dos movimentos sociais com as disputas sociais e políticas existentes e com o Estado.

No que tange à relação de movimentos sociais com o "jogo"2 social e político estabelecido, teorias norte-americanas sobre a ação coletiva - destacando-se aqui a teoria do processo político (TPP) e a teoria do confronto político (ou contentious politics) - sugerem que movimentos sociais são empreendimentos coletivos que buscam acesso aos recursos disputados nesse jogo, adaptando-se às suas regras, lógicas e configurações para aprimorar seu desempenho e suas possibilidades de ganho nele. Na medida em que, na maior parte das sociedades capitalistas contemporâneas, o Estado é o ator responsável pela captação, administração e distribuição de grande parte desses recursos, essa abordagem enfatiza a interdependência da ação de movimentos sociais em relação às dinâmicas da política institucionalizada, bem como uma relação de confronto entre esses dois atores.

$\mathrm{Na}$ formulação clássica da TPP, o interesse de movimentos sociais pelos recursos disputados no "jogo" estabelecido e sua relação conflituosa com o Estado são visíveis. McAdam (1982) define movimentos sociais como grupos cujos interesses não são contemplados pela agenda política institucional (os outsiders) e que, portanto, organizam-se para pressionar os indivíduos inseridos nessas instituições (os membros) para que dirijam os recursos estatais para o atendimento de suas demandas (McAdam, 1982).

Já os conceitos de oportunidades políticas e repertórios de ação coletiva demonstram a ênfase dessa abordagem na interdependência entre a ação de movimentos sociais em relação às dinâmicas estatais, bem como na tendência de adaptação de atores coletivos contestatórios às modificações na configuração do "jogo" estabelecido. O conceito de oportunidades políticas sugere que movimentos sociais tendem a se mobilizar na medida em que sejam identificadas oportunidades "oferecidas pelo jogo" relacionadas a mudanças no Estado, tais como a ampliação do acesso às instituições, a ocorrência de mudanças nos alinhamentos políticos, a divisão entre as elites, a obtenção de aliados influentes e a diminuição das atividades de repressão do Estado. Já o conceito de repertórios de ação coletiva sugere que a ação de movimentos sociais segue padrões culturais historicamente estabelecidos que tendem

\footnotetext{
${ }^{2}$ A metáfora do "jogo" se refere às instituições sociais, políticas e culturais estabelecidas, bem como aos seus pressupostos normativos e de eficácia.
} 
a se modificar na medida em que ocorrem mudanças nos regimes políticos. Dessa forma, em ambos os casos, é enfatizada a adaptação de movimentos sociais a modificações conjunturais do "jogo", percebidas como intimamente relacionadas a mudanças nas dinâmicas estatais, estabelecendo-se, assim, uma interdependência entre esses atores (Alonso, 2012; Tarrow, 2009; Tilly, 1976).

Por fim, os debates estabelecidos em torno do principal conceito mobilizado por essa tradição teórica para compreender a dimensão simbólica da ação coletiva - o conceito de enquadramento interpretativo - também demonstram essa ênfase na adaptação. Ao defender que mensagens produzidas por movimentos sociais obtêm "ressonância" apenas quando nelas podem ser identificados pontos em comum às percepções e aos valores socialmente estabelecidos e generalizados, essa literatura aponta para o constante imperativo de adaptação do enquadramento produzido por organizações de movimentos sociais à cultura vigente (Benford e Snow, 2000; Noakes e Johsnton, 2005).

Já as chamadas teorias dos novos movimentos sociais (TNMS) desenvolvidas no contexto europeu de produção do conhecimento oferecem visões distintas a respeito desses temas. Apesar de diversas, em linhas gerais, essas teorias apontam que grandes transformações do sistema capitalista ao longo do século XX - como o enfraquecimento do estado-nacional, a internacionalização da economia e a perda de centralidade das relações industriais (política e simbólica, não econômica) - deram origem a novos modos de contestação política que se distanciam do formato clássico do movimento operário (Alonso, 2009; Dubet, 1996; Dubet e Thaler, 2004; Touraine, 1997). Essas novas formas de ação coletiva são caracterizadas a partir do distanciamento e da busca de autonomia em relação ao Estado, bem como a partir do objetivo de questionamento das bases simbólicas do "jogo" social estabelecido pela política institucional e pelo mercado.

Touraine $(1989 ; 1997)$ caracteriza esse novo conflito social por meio de uma oposição entre o desejo de auto-definição e de garantia de direitos expresso pelo conceito de "sujeito" e as exigências da tradição e do mercado. Essa profunda cisão da realidade social, entre uma esfera subjetiva, expressiva e moral e outra baseada nas pressões das instituições e na ação instrumental, faz com que os valores percam sua unidade, instituindo uma permanente tensão entre a vocação do sujeito e os requerimentos de eficácia (Dubet e Martuccelli, 1999, p. 324). É possível identificar em Touraine uma afirmação normativa da proeminência da afirmação do sujeito autônomo, sobre as concepções instrumentais e tradicionais, sugerindo-se que "verdadeiros movimentos sociais" devem lutar pela afirmação do "sujeito" frente às demandas sociais competidoras. 
A construção de novas perspectivas culturais que questionem as bases simbólicas do jogo social é também um aspecto central na abordagem desenvolvida por Melucci (1989; 1995), baseada no conceito de "identidades coletivas". Segundo o autor, as novas formas de dominação no capitalismo estariam conectadas não mais à simples exploração crescente da força de trabalho, mas sim à construção de identidades funcionais à reprodução do sistema. Nesse sentido, movimentos sociais buscariam denunciar essas formas simbólicas de dominação construindo identidades coletivas que as questionem a partir de entendimentos próprios e negociados de si mesmos e dos outros. Opondo-se à ideia de que movimentos sociais se relacionam ao "jogo" apenas disputando os recursos por ele oferecidos, Melucci (1989, p. 59) defende que esses atores "não lutam meramente por bens materiais ou para aumentar sua participação no sistema. Eles lutam por projetos simbólicos e culturais, por um significado e por orientações diferentes da ação social”.

Assim, essas tradições teóricas oferecem visões distintas sobre a orientação de movimentos sociais em relação ao "jogo" estabelecido e ao Estado. Aquilo que poderia se configurar em uma simples disputa teórica a respeito do entendimento de dados fenômenos se traduz, no entanto, em uma disputa de projetos políticos, na medida em que essas teorias são, em muitos casos, tratadas normativamente (Silva, 2010). Nesse sentido, não se estabelece apenas uma disputa teórica sobre "o que são movimentos sociais", mas uma disputa sobre "o que movimentos sociais deveriam ser" dentro do campo de estudos da ação coletiva. Sociólogos assumem para si, dessa forma, um dilema e uma disputa entre confrontar e se relacionar com o Estado ou se afastar de sua influência em busca de autonomia; entre se adaptar às regras e modificações do "jogo" social em busca dos resultados por ele oferecidos ou construir novos consensos e identidades que minem a reprodução sistêmica desse "jogo" na qual ocupam uma posição marginal.

\section{2 - Dilemas ausentes: Projetos de síntese}

Reflexões teóricas contemporâneas sobre a ação coletiva têm fornecido importantes ferramentas conceituais para a superação das cisões e dicotomias teóricas estabelecidas por esse debate. Por um lado, teóricos têm enfatizado que a ação coletiva contestatória não pode ser caracterizada por apenas uma forma ou lógica de ação, havendo a presença simultânea de inúmeras orientações para a ação de indivíduos e organizações. Por outro lado, estudiosos têm apontado para as fragilidades da dicotomia entre o estabelecimento de relações com o Estado e a autonomia dos movimentos sociais, aprofundando o pressuposto de que movimentos 
sociais podem ter relações com a política institucional e analisando as interpenetrações e sobreposições entre espaços institucionais e espaços extra-institucionais de militância política.

No que tange ao primeiro desses aspectos, antropólogos latino-americanos têm tentado demonstrar que a ação coletiva é permeada, ao mesmo tempo, por uma lógica de obtenção de benefícios econômicos e materiais tendo em vista as oportunidades oferecidas aos atores e por uma lógica crítica às bases simbólicas desse "jogo" estabelecido, em busca de autonomia e transformação (Auyero, 1999; 2005; Quirós, 2005). Em seu estudo sobre "clientelismo" na Argentina, por exemplo, Auyero (1999) critica a interpretação de que esse fenômeno poderia ser reduzido a uma "mera" troca de benefícios materiais por apoio político. Em busca do "ponto de vista dos clientes", esse autor descreve uma variedade de interpretações ligadas àquilo que costumeiramente é caracterizado pelo conceito de "clientelismo", que variam desde a interpretação de que essa seria uma simples "compra de apoio" até interpretações que as concebiam como uma relação de confiança, gratidão e reciprocidade.

Estendendo as reflexões propostas por esse autor, Quirós (2005) identifica na literatura sobre movimentos sociais uma cisão entre a "razão política e ideológica" e a "razão econômica e material" que se expressaria nas dicotomias entre: ação orientada pelo altruísmo e ação orientada pelo interesse; ação voluntarista e ação movida pela obrigação; e, por fim, entre desejo de autonomia em relação ao "jogo" estabelecido em uma busca de sua transformação e o estabelecimento de relações de dependência para a garantia de benefícios nesse "jogo" que levaria à reprodução das desigualdades. Limitados por essa dicotomia, teóricos teriam dificuldade em reconhecer que uma forma de engajamento pode conduzir a outra e que a ação não se limita a uma dessas orientações. Dessa forma, a autora propõe que o estudo da ação coletiva não deveria disputar projetos normativos de classificação de ações em uma dessas categorias (que culminaria na legitimação de apenas alguns atores como movimentos sociais), mas sim na compreensão de que a ação política tem motivações múltiplas - políticas, econômicas, materiais e simbólicas - que estão sempre interconectadas (Quirós, 2005).

Já no que se refere às relações entre movimentos sociais e Estado, autores têm criticado o chamado "pressuposto da externalidade", que assumiria que movimentos sociais são (ou devem ser) atores externos às esferas da política institucional. De maneiras diferentes, ambas as tradições teóricas citadas reproduziriam esse pressuposto. Por um lado, apesar de reconhecerem inúmeras formas de relação entre movimentos sociais e Estado, teóricos norteamericanos tenderiam a tratar ativistas como indivíduos completamente afastados dos espaços institucionais de participação (como outsiders) em uma constante oposição aos atores neles 
inseridos, estabelecendo-se sempre uma relação conflituosa entre ativistas e atores relacionados à política institucional. Já as TNMS, a partir de seus pressupostos normativos, tenderiam a opor as possibilidades de autonomia e de ação transformadora a qualquer influência estatal na ação de movimentos sociais, negando o status de ativista àqueles que se envolvem com a política institucional e negando a possibilidade de que a ação coletiva nessa arena possa produzir resultados vistos como favoráveis pelos militantes (ideia comumente resumida pela noção de “cooptação”) (Abers e Von Büllow, 2011; Goldstone, 2003; Silva, no prelo).

Ao contrário do que supunham as teorias anteriormente analisadas sobre o tema, estudos empíricos têm apontado que ativistas, em geral, buscam conciliar repertórios institucionais e extra-institucionais. Mais do que alternar esses repertórios, estudos identificam que ativistas buscam ocupar espaços dentro da própria estrutura estatal, seja por meio da criação de redes com atores nela inseridos, seja pela ocupação de espaços institucionais pelos próprios militantes (tal como na ocupação de cargos em conselhos, secretarias e ministérios) sem que isso signifique uma submissão dos indivíduos às lógicas do Estado e um abandono do desejo de transformação social mais ampla (Abers e Von Büllow, 2011; Goldstone, 2003; Leitão, 2012; Silva e Oliveira, 2011).

Esses dois conjuntos de reflexões teóricas trazem uma importante contribuição ao propor que perspectivas sociológicas não podem cair em armadilhas dicotômicas que opõem a busca pelos resultados oferecidos pelo "jogo" social e o estabelecimento de relações e parcerias com o Estado à crítica às próprias bases desse jogo em busca da autonomia em relação às instituições políticas e econômicas vigentes. Estudiosos reconhecem, no entanto, que empiricamente essa é uma questão polêmica. Nas relações entre ativistas e organizações de um mesmo movimento social, por exemplo, pode ser facilmente identificado um forte conflito em relação ao estabelecimento de parcerias com o Estado e em relação à adaptação de suas demandas, mensagens e repertórios às possibilidades de sucesso imediato vislumbradas no contexto social estabelecido. Como descrevem Abers e Von Büllow:

[...] participar ou não dessas arenas oficiais tem sido um tema extremamente polêmico. Enquanto alguns movimentos sociais têm rejeitado sistematicamente essa possibilidade, outros movimentos sociais têm tentado utilizar o Estado como plataforma a partir da qual dar maior visibilidade e eficácia às suas demandas (Abers e Von Büllow, 2011, p. 66)

Porém, se assumirmos teoricamente que tanto a lógica de adaptação ao jogo quanto a lógica de crítica ao jogo convivem harmoniosamente orientando a ação do indivíduo, bem 
como se assumirmos teoricamente que a relação com o Estado não implica necessariamente um abandono da autonomia e da busca pela transformação das regras desse jogo, como podemos explicar a existência desses dilemas empíricos? Mesmo se apontarmos que o estabelecimento de relações com o Estado e a adaptação às regras do jogo geram um novo padrão de interações no qual a hierarquia e a tendência à moderação estão presentes, como fazem Abers e Von Büllow (2011), como explicar que atores que compartilham um mesmo projeto de transformação social e que estão inseridos no mesmo recorte espaço-temporal proponham linhas de ação tão distintas ${ }^{3}$ ?

Nesse ponto, o arsenal teórico que produz a superação de determinados dilemas sociológicos parece não oferecer alternativas conceituais para lidar com os dilemas empíricos. Este trabalho busca, na sociologia da experiência de François Dubet, tais definições teóricas.

\section{3 - Dilemas empíricos da ação coletiva: a experiência problemática}

A sociologia da experiência parte de uma interrogação em torno da questão da ação social: como construir uma teoria do social que dê conta, ao mesmo tempo, do fazer história pelos homens e das limitações existentes? (Dubet e Martuccelli, 1999). Pode-se identificar um conjunto de respostas clássicas a esse problema, também ele clássico, que repousam na concepção da sociedade como um sistema funcional, do qual a ação social é tão somente a sua vertente subjetiva. Assim, nessa perspectiva ampla, da qual Durkheim e Parsons são expressões intensas, constrói-se uma resposta à tensão entre ação e estrutura a partir do postulado de que o ator é o sistema. Dessa forma, o ator era definido como interiorização social, sendo a sua ação não mais que a realização das normas e necessidades funcionais do sistema social encarnadas em valores institucionalizados nos papéis interiorizados pelo indivíduo (Dubet, 2007).

As perspectivas apresentadas anteriormente neste artigo têm em comum a crítica, latente ou manifesta, da concepção clássica da ação social expressa de forma particular em parte dos estudos sobre os movimentos sociais anteriores às décadas de 1960 e 1970, que

\footnotetext{
${ }^{3}$ Leitão (2012) busca compreender os motivos do fortalecimento da opção pela ação institucional do movimento negro brasileiro a partir da década de 1980. Seu modelo explicativo está baseado na modificação do contexto político que engendraria uma mudança na interpretação dos atores a respeito das ameaças a oportunidades que o Estado representa. A questão sobre os motivos pelos quais, em um mesmo momento histórico, ativistas se debruçam sobre o dilema de estabelecer ou não esse tipo de relação é menos explorada, mas relacionada a diferentes atribuições de oportunidades e ameaças. Admitindo essa possibilidade, o argumento desenvolvido neste trabalho busca compreender essas diferentes percepções ao afirmar que ativistas estipulam diferentes objetivos prioritários de curto prazo, de acordo com distintas combinações de lógicas de ação, sendo as ameaças e oportunidades interpretadas, portanto, em relação a esses objetivos variados, gerando interpretações divergentes a respeito delas.
} 
destacavam a correlação entre estruturas de sociedade e estruturas de personalidade (Alonso, 2009). Assim, constituíram-se dois espaços nos estudos sobre os movimentos sociais, descritos na primeira parte. Por um lado, em âmbito norte-americano, destacava-se sobretudo a dimensão racional da ação coletiva, enquanto, por outro lado, na Europa se chamava a atenção para o aspecto identitário desse processo. Os esforços de síntese, destacados na segunda parte, afirmam e procuram demonstrar que a ação coletiva pode ser permeada por várias lógicas de ação, assim como de múltiplos modos de se relacionar com o Estado. Contudo, apesar de relevantes, tais esforços tendem a ocultar a tarefa contingente de constituição e articulação de lógicas da ação por parte dos movimentos sociais.

No intuito de propor um possível caminho para a consecução de tal tarefa, partiremos da concepção da ação social como experiência social (1996). Identificar a pluralidade da ação é o primeiro passo, porém, faz-se necessário ainda, compreender a dupla pluralidade tendencialmente contraditória que marca a ação social contemporânea (Speroni, 2012). Isso significa dizer que é relevante compreender não só quais são as lógicas presentes nos movimentos sociais, mas quais são as formas em que essas lógicas são articuladas e como as possíveis tensões entre tais se fazem presentes. Em outras palavras, como os atores coletivos constituem a sua experiência social (Dubet, 1996).

\section{1 - A sociologia da experiência}

Para Dubet não é aceitável conceber a ação social enquanto unicamente determinada pelos códigos interiorizados ou como encadeamentos de opções estratégicas e racionais (Dubet, 1996; Dubet e Martuccelli, 1999), o que demanda uma passagem da ação enquanto papel, estratégia ou utilidade para a ação como articulação de múltiplas racionalidades e práticas. A noção de experiência social foi concebida por Dubet no intuito de expressar a pluralidade e heterogeneidade tanto do sistema quanto da ação social, destacando o trabalho do ator nesse espaço de ambivalências, contradições e tensões. Assim, concebe-se o sistema e a ação social como desprovidos de unidade, sendo tarefa do indivíduo a constituição de coerência em um mundo incongruente.

A experiência social é, na definição de Dubet, o produto de uma atividade do ator em um meio social plural que ele não controla. Desse modo, ela

(...) designa condutas individuais e coletivas dominadas pela heterogeneidade dos seus princípios constitutivos, e pela atividade dos 
indivíduos que devem construir o sentido de suas práticas no próprio seio desta heterogeneidade (Dubet, 1996, p. 15).

Essa noção alude, portanto, mais a um fazer do que a um ser (Dubet, 1996). Segundo Dubet, "a experiência social é uma atividade cognitiva, é uma maneira de construir o real e, sobretudo, de o "verificar", de o "experimentar" (Dubet, 1996, p. 95).

A sociologia da experiência proposta por Dubet fundamenta-se em três postulados sobre a ação social: (i) a ação é desprovida de unidade ${ }^{4}$; (ii) a ação não é só formada por orientações normativas e culturais, mas também alude a formas de relação com o outro ${ }^{5}$, (iii) a experiência social é uma combinatória de princípios constitutivos da ação articulados por atores "concretos". Assim, caberia ao sociólogo isolar e descrever as lógicas de ação presentes em um processo dado; compreender o modo como os atores articulam as distintas lógicas; e partir da ação em direção ao sistema social a fim de explicar “(...) as diferentes lógicas do sistema social mediante a forma como os atores as sintetizam e as catalisam tanto no plano individual quanto coletivo" (Dubet, 1996, p. 112) ${ }^{6}$.

Para o autor, as lógicas de ação têm como origem os três distintos sistemas sociais por ele identificados (Dubet, 1996): um sistema de integração, o que foi, durante longa data, identificado como a ideia de comunidade; um sistema de competição, permeado por múltiplos mercados econômicos e não econômicos; e o sistema de ação histórico, que emerge das tensões entre a cultura e as relações sociais, aludindo, assim, a um espaço que não pode ser reduzido à tradição ou à utilidade (Dubet, 1996). O autor aponta que

(...) cada um destes elementos é sustentado por uma lógica própria e definese num campo e num espaço particulares: geralmente, as comunidades são nacionais, locais, "étnicas"..., o mercado é internacional, a cultura é hoje em dia a dos indivíduos (Dubet, 1996, p. 113).

Assim, existem três lógicas de ação autônomas e não hierarquizadas, cuja articulação forma a experiência social, e que correspondem a cada um dos sistemas mencionados: a de integração, a de estratégia e a de subjetivação.

A lógica de integração faz referência à perspectiva da sociologia clássica, que promulgava o postulado da continuidade entre a objetividade do sistema e a subjetividade do

\footnotetext{
${ }^{4}$ A referência a Weber é, assim, evidente quando Dubet postula que a ação é perpassada por uma diversidade não hierárquica de lógicas de ação autônomas que estão em tensão e que travam uma guerra interna ao indivíduo (Dubet, 1996).

${ }^{5}$ As lógicas de ação que atravessam a experiência social possuem duas dimensões: "Não é o sentido vivido pelo ator que determina a natureza das relações nas quais ele está envolvido, como não são tampouco essas relações que fixam o sentido da ação." (Dubet, 1996, p. 111). Esses dois aspectos emergem simultaneamente em uma lógica de ação, visto que "dar um sentido a uma ação é, ao mesmo tempo, atribuir um estatuto ao outro" (Dubet, 1996, p. 111).

${ }^{6}$ A proposta final deste trabalho articula apenas as duas primeiras dessas tarefas.
} 
ator. Apesar de essa representação do social estar em crise, seu esgotamento não é total. Essa lógica refere-se, portanto, aos mecanismos de integração social, que fazem com que o ator internalize valores institucionalizados por meio de papéis (Dubet, 1996) e que definem, pelo menos em parte, o ator pela sua interiorização do social (Dubet, 1996). A identidade do ator, sob essa lógica, é a do seu papel social (Dubet, 1996). Destaca-se, portanto, que, por mais moderna que seja a vivência de um indivíduo, não há como não haver uma identificação por meio de uma filiação, de um nome ou pelo aferro a certos valores "comunitários" (nacionais, locais, étnicos etc.), mesmo que ela se dê de uma forma quase que subconsciente. Assim, nessa lógica, a natureza das relações sociais vinculadas à identidade integradora institui-se pela oposição entre o "nós” e o “eles” (Dubet, 1996).

Se, na lógica da integração, a sociedade é vista como um conjunto integrado evocado pela ideia de comunidade, sob a lógica estratégica, a sociedade é vista enquanto um campo concorrencial, sendo marcada por múltiplos mercados, tanto econômicos quanto não econômicos. A identidade dos atores sob a lógica estratégica vincula-se ao conjunto de recursos mobilizados em intercâmbios sociais circunstanciais (Dubet e Martuccelli, 1999). Neste sentido, essa lógica faz referência à ação racional em relação aos meios, tal como descrevia Weber (Dubet, 2011). A lógica estratégica é mobilizada tanto por atores individuais quanto coletivos, tal como é demonstrado pelas teorias de mobilização de recursos, que identificam certa instrumentalização da identidade, de sentimentos de pertença e de solidariedade. Nesse sentido, as relações sociais são descritas sob essa lógica em termos de concorrência, permeadas pelos interesses coletivos ou individuais. A estratégia se desenvolve de forma análoga ao jogo, visto que a vitória não reclama a destruição do outro (como na guerra) e tem o elemento concorrencial como central (diferentemente da ordem comunitária). Assim, o outro é, ao mesmo tempo, um possível rival ou aliado (Dubet, 1996).

A terceira lógica, a da subjetivação, emerge pela via indireta de uma atividade crítica do sujeito (Dubet, 1996) fundamentada na sua distância em relação ao sistema e na incompletude das explicações relativas aos papéis sociais e as que fazem referência às estratégias $^{7}$. As lógicas anteriores não explicam o fato de que os atores se consideram enquanto sujeitos de desejo, sendo mais ou menos capazes de serem o centro de sua ação, assim como não são capazes de explicar a atividade crítica que perpassa a atividade dos atores

\footnotetext{
${ }^{7}$ Se a experiência social é uma combinação, ou seja, se os atores são impelidos a agir em distintos registros de ação, é necessário que, em alguma medida, eles sejam sujeitos, a fim de que possam lidar com as tensões das lógicas, o que, evidentemente, obriga-os a estar em relativa distância a estas: "Os "eu" da integração e os "eu" da estratégia supõem que um "eu" seja capaz de manter uma unidade da pessoa sem se identificar plenamente com esses diversos 'eu'” (Dubet, 2011, p. 121, tradução nossa).
} 
(Dubet, 2011). Esta atividade crítica, tão logo é acionada, passa a estar em plena tensão com as lógicas de integração e de estratégia. Do ponto de vista dessa lógica, as relações sociais são vistas em termos de barreiras ao reconhecimento e à expressão dessa subjetivação; a sociedade assim é percebida enquanto "sistema de dominação que se opõe à autorrealização dos atores" (Dubet, 2011, p. 122, tradução livre). Sob essa lógica, o conflito social é perpassado não por uma busca de preservação da identidade (relativa à lógica da integração), nem como uma ação orientada ao sucesso (caso da lógica da estratégia), mas sim enquanto uma luta contra a alienação, entendida como incapacidade de ser autônomo, devido a processos de dominação social que reduzem os atores a suportes dos papéis ou a agentes de interesses limitados e determinados pelos poderosos ou pelo próprio "sistema" (Dubet, 1996).

Dubet identifica a existência das três lógicas mencionadas, não sendo nenhuma delas capaz de explicar a ação social de forma isolada. Assim, na inexistência de um ponto central da ação, a combinatória de lógicas emerge como uma característica da vivência dos atores e como um imperativo para a análise sociológica. Em um mundo incapaz de garantir uma coerência antecipada à ação social - onde as classes não podem mais serem concebidas enquanto "seres sociais totais", a subjetivação e a socialização se separaram, e as identidades culturais se multiplicaram -, os atores são levados a trabalhar na construção do arranjo de sentidos a fim de fundamentar a sua ação social (Dubet, 1996). O objeto da sociologia da experiência proposta por Dubet é analisar este trabalho do ator, que não se restringe ao seu papel, aos seus interesses, nem à sua cultura (Dubet, 1996).

Em suma, a sociologia da experiência coloca como problema central o de compreender como os atores compõem suas experiências sociais em diferentes condições, situações e posições sociais ao enfrentar as distintas exigências advindas dos sistemas sociais e suas lógicas. Desse modo, essa perspectiva sociológica vai além da identificação da heterogeneidade do social no sentido de afirmar a existência de uma dupla tendencialmente contraditória (Speroni, 2012). Isso significa dizer que há, por um lado, uma multiplicidade de lógicas de ação e, por outro, que essas lógicas tendem a estar em tensão entre si, o que leva a necessidade de um esforço dos atores para compor as suas experiências sociais, enfrentando as contradições desse processo.

\section{2 - A ação coletiva como experiência social}

A partir desses pressupostos teóricos, Dubet defende que a ação coletiva tem seu sucesso não somente na inserção do Ego em um Nós superior ou no incremento de sua 
capacidade organizativa, mas igualmente na força da autonomia individual (Dubet, 1996). Assim, os movimentos sociais são atravessados por uma tarefa análoga à dos indivíduos. A articulação de sentidos da ação coletiva não é dada a priori e se mostra enquanto um aspecto permeado por inúmeras dificuldades, impedindo uma integração das lógicas de ação. Em síntese:

(...) a sociedade apresenta-se como um campo de lutas dispersas. E, do mesmo modo que os indivíduos são obrigados a construir a sua experiência, também os movimentos devem articular constantemente significações relativamente heterogêneas (Dubet, 1996, p. 228).

Adaptando tais pressupostos da sociologia da experiência às teorias dos movimentos sociais, Pereira (2014) produz uma tipologia de combinações de lógicas de ação no estudo do movimento pelos direitos animais. Nesta seção, tais combinações são teoricamente descritas e ilustradas com exemplos de uma pesquisa empírica realizada junto ao movimento dos direitos animais em Porto Alegre entre os anos de 2012 e 2013.

Sugere-se que três lógicas são combinadas na ação coletiva, estando relacionadas a diferentes objetivos de ação: a lógica construcionista, a lógica pragmática e a lógica identitária ${ }^{9}$. Combinando-as, os atores tendem a priorizar uma dessas lógicas, concebendo que os objetivos por ela estipulados são, ao mesmo tempo, aqueles que, devido a um imperativo moral, devem ser perseguidos como prioritários e, devido a um imperativo de eficácia, são vistos como aqueles que conduzem às condições de realização dos objetivos relacionados às lógicas subordinadas.

Quando ativistas se orientam por uma combinação construcionista de lógicas de ação, é estabelecido como objetivo geral de curto prazo a construção de novos problemas sociais, questionando as bases simbólicas que definem "o que está em disputa" no "jogo". Assim, ativistas buscam construir novas interpretações sobre situações antes vistas como normais ou como problemas pessoais. Nesse caso, interações com o Estado podem ser concebidas pelos atores como ameaças à autonomia dos movimentos sociais, na medida em que mesmo

\footnotetext{
${ }^{8}$ A descrição dessa atividade do ator (individual e coletivo) realizada até o momento não pode levar à ideia de total ausência de sentido e de unidade. $\mathrm{O}$ aspecto que Dubet procura destacar é que o sentido da vivência dos atores "(...) já não é "dado" pela vida social e pela unidade do sistema, ele é o produto de uma atividade muito frequentemente rotinizada, mas, apesar de tudo, de uma atividade. Esta atividade que produz a imagem de um sujeito permanece ligada à representação histórica e cultural de um sujeito que é, hoje em dia, a imagem de um indivíduo, quer dizer, de um ator autônomo que constrói a sua própria vida contra o que se lhe opõe e contra as outras duas imagens do indivíduo, a do Ego da integração e a do Homo economicus no centro da ação estratégica" (Dubet, 1996, p. 228).

9 Essas lógicas são teoricamente inspiradas, respectivamente: na lógica da subjetivação de Dubet (1996), na teoria construcionista dos problemas sociais e em elementos das chamadas TNMS (Ibarra e Kitsuse, 1992; Touraine, 1997); na lógica da estratégia de Dubet (1996) e nas teorias norte-americanas da ação coletiva (McAdam, 1982; Tarrow, 2009; Tilly, 1976); na lógica da integração de Dubet (1996) e no conceito de "identidade coletiva" (Melucci, 1995).
} 
questões construídas nas arenas científica e midiática como problemas sociais podem ser vistas como não merecedoras de intervenção estatal imediata pelas instituições políticas formais (Hannigan, 2009) ${ }^{10}$. Ainda, mesmo que atores inseridos em tais instituições considerem a intervenção legítima, a demanda dos movimentos sociais deve competir pela atenção limitada do Estado, presente, principalmente, em sua dinâmica macropolítica (True et al., 2007).

No caso da militância a favor dos direitos animais, ativistas que se guiam por essa combinação buscam, prioritariamente e em curto prazo, construir a exploração animal como um problema social, questionando as bases simbólicas das relações estabelecidas entre animais humanos e não humanos. Articulando a lógica construcionista com as demais lógicas do ponto de vista do imperativo moral, militantes alegam, com base em filósofos como Gary Francione, que a ação moral é aquela que questiona as desigualdades estabelecidas por meio de ações educativas (Francione, 2007). Já do ponto de vista do imperativo de eficácia, militantes defendem que indivíduos não abolicionistas se tornam veganos ao se depararem com os problemas éticos da exploração a animal e que os atores capazes de atuar para superar esse problema (tais como o Estado) fariam isso apenas depois de uma conscientização mais ampla da sociedade (havendo uma relação causal de eficácia na seguinte ordem: construir, atrair, conquistar) (Pereira, 2014).

Já quando ativistas se orientam por uma combinação pragmática de lógicas de ação, é estabelecida como objetivo geral de curto prazo a obtenção dos resultados (materiais ou simbólicos), vistos como "possíveis" de serem obtidos de acordo com o seu diagnóstico das oportunidades políticas e culturais oferecidas pelo "jogo", buscando a diminuição ou a abolição dos problemas enfrentados pelos beneficiários da ação coletiva. Nesse caso, interações com o Estado tendem a ser vistas como essenciais, na medida em que este é um espaço no qual recursos são oferecidos em abundância para diversos atores sociais.

No caso da militância pelos direitos animais, frente à ideia de que um "mundo especista" impõe obstáculos políticos e culturais para o avanço da "agenda abolicionista", ativistas buscam, prioritariamente e em curto prazo, a conquista dos resultados vistos como "possíveis" no contexto atual que, mesmo que não garantam a transformação das concepções

\footnotetext{
${ }^{10}$ Hannigan (2009), por exemplo, propõe que problemas ambientais passam por três fases (não necessariamente, mas potencialmente, subsequentes) de construção social. Na primeira delas, os problemas são definidos e "identificados", em geral, pela comunidade científica. Na segunda, ativistas buscam atrair a atenção de grandes veículos de comunicação, tornando-os públicos. Por fim, militantes devem conquistar ações estatais que possam combater os problemas construídos. A passagem por essas "fases", no entanto, não é automática. Assim, segundo Hannigan (2009, p.112), "mesmo se um argumento ambiental consegue transcender o limite da legitimidade, isso não assegura que uma ação para melhorar vai ser tomada (...). Um problema pode ser transformado em uma questão menos ameaçadora. Os oponentes, dentro da burocracia governamental, podem usar várias táticas (...) as quais asseguram que um problema não seja imediatamente ativado".
} 
morais que orientam as relações de homens e animais, possam aliviar as condições de exploração às quais os animais são submetidos ou abolir essa exploração em determinados contextos. Combinando a lógica pragmática às demais lógicas, do ponto de vista da moralidade, ativistas sugerem, com base em filósofos como David Stzybel e Carlos Naconecy, que a ação moral é aquela que "produz o melhor para os seres sencientes em todos os momentos" (Naconecy, 2009; Stzybel, 2007). Do ponto de vista da eficácia, ativistas alegam que indivíduos e organizações (tais como grandes empresas ou o Estado) não guiam suas ações baseados em princípios éticos, mas sim por princípios práticos (tais como a conquista de benefícios econômicos ou políticos imediatos) que serão justificados por concepções morais criadas posteriormente. Dessa forma, defendem a necessidade de aproveitar a lógica estabelecida no jogo para ganhar "aquilo que é possível”, construindo paulatinamente, por meio desses avanços, moralidades e identidades que sustentem as práticas consideradas éticas pelos ativistas (havendo uma relação causal de eficácia na seguinte ordem: conquistar, construir, atrair) (Pereira, 2014).

Por fim, ativistas que se guiam por uma combinação identitária de lógicas de ação buscam, prioritariamente e em curto prazo, construir ou reafirmar suas identidades coletivas, vistas como novas ou repensadas em relação às categorias de identificação socialmente disponíveis, difundindo essas definições próprias. Novamente, nesse caso, interações com o Estado tendem a ser vistas pelos atores como ameaças à autonomia dos movimentos sociais, na medida em que a política institucional, por meio dos desenhos de suas políticas públicas, tende a produzir imagens dos atores sociais não necessariamente condizentes às formas pelas quais esses atores concebem a si mesmos (Ingram et al., 2007).

No caso do ativismo em defesa dos direitos animais, ativistas têm como objetivo principal divulgar o veganismo, suas características e seus benefícios, questionando estereótipos e preconceitos, bem como demonstrando que a adoção de tais hábitos é viável. Combinando a lógica identitária com as demais lógicas, do ponto de vista moral, ativistas enfatizam a dimensão da moralidade das práticas individuais e a importância do veganismo como prática moral com valor em si mesma. No que tange ao princípio de eficácia, ativistas identitários sustentam que indivíduos não abolicionistas não tomam decisões, necessariamente, guiados por convicções éticas ou por interesses imediatos, mas pela tomada de conhecimento de novas possibilidades de condução de sua própria vida. O veganismo seria uma "armadilha", já que, ao se aproximarem dos hábitos veganos por qualquer motivo, indivíduos não abolicionistas iriam, inevitavelmente, entrar em contato com o diagnóstico de 
exploração animal, passando a lutar e gerar resultados práticos para os animais (havendo uma relação causal de eficácia na seguinte ordem: atrair, construir, conquistar) (Pereira, 2014).

\title{
Por um deslocamento compreensivo do debate
}

Os debates "clássicos" entre teorias norte-americanas da ação coletiva e as TNMS tiveram um papel fundamental na identificação das diversas "naturezas" da ação coletiva. Já as perspectivas sintéticas avançam no sentido de não tomar essas orientações distintas da ação como excludentes, mas sim como formas coexistentes de ação coletiva. É necessário, no entanto, um olhar teórico que, a partir do diagnóstico da sobreposição de espaços e repertórios, não obscureça os dilemas presentes na ação coletiva.

Além de demandar novos postulados teóricos, essa nova orientação teórica leva à necessidade de uma redefinição do papel do sociólogo frente à ação social. Desse modo, no âmbito deste estudo, sugere-se, a partir da sociologia da experiência de Dubet, que a sociologia deva renunciar à tarefa de construir narrativas homogeneizantes, que constroem "soluções" para os dilemas da ação social, especialmente da ação coletiva, assumindo que os dilemas da ação são construídos e respondidos por atores concretos que compõem a sua experiência em um mundo social fragmentado e que não possuem controle. Uma sociologia da ação coletiva que admite isso deve procurar compreender como atores, em diferentes condições e com distintos objetivos, articulam lógicas de ação plurais e tendencialmente contraditórias. No decurso de tal tarefa, postula-se aqui que se torna possível um acréscimo de qualidade de descrições empíricas, assim como se possibilita a identificação de mecanismos causais dotados de real caráter explicativo.

\section{COLLECTIVE ACTION DILEMMAS: A SOCIOLOGICAL LOOK AT THE TENSIONS OF EXPERIENCE}

\begin{abstract}
The collective action study field, especially, during the decades of 1970 and 1980, was marked by intense disputes between, at the one hand, approaches that emphasized the "instrumental" action of social movements aiming the scarce resources controlled by the State and, at the other, approaches that emphasized the "ideological" action of these actors aiming the creation of new cultural perceptions that could promote their autonomy in relation to the requests of the market and of the tradition. Since this period, synthetic efforts that aim to connect both of these collective action dimensions can be observed. These new perspectives
\end{abstract}


can be characterized by the deconstruction of dichotomies and by the affirmation that different rationalities and motivations are always present in social action, highlighting that interactions between State and social movements do not imply, necessarily, in an autonomy loss for contentious collective actors. In this article, it is theoretically postulated that, if this synthetic project enables a withdrawal from normative assumptions about "what is politics", it is necessary that the designed conceptual tools make possible the comprehension that this is a question that is, in a daily basis, put in dispute among contentious collective actors. It is proposed that the theoretical framework developed by the sociologist François Dubet provides important reflections for the construction of an appropriate model for this task. Through these reflections, it is proposed a displacement of the sociological approach for collective action, abandoning the task of theoretical resolution of dilemmas that are, essentially, empirical, towards a comprehensive stance about how these tensions are solved by actors that are actually involved in contentious collective actions.

Keywords: dilemmas; social movements; logics of action.

\section{DILEMAS DE LA ACCIÓN COLECTIVA: UNA MIRADA SOCIOLÓGICA A LAS TENSIONES DE LA EXPERIENCIA}

\section{Resumen}

El campo de estudio de la acción colectiva, principalmente durante las décadas de 1970 y 1980 se caracterizó por intensas disputas entre, por una parte, los enfoques que resaltaban la acción "instrumental" de los movimientos sociales en la búsqueda de los escasos recursos controlados por el Estado y, por otra parte, las perspectivas que hacían hincapié de la acción "ideológica" de estos actores en su objetivo de crear nuevas percepciones culturales que fomentaran su autonomía frente a las demandas del mercado y de la tradición. Desde entonces, se puede observar los esfuerzos de síntesis que tratan de vincular estas dimensiones de la acción colectiva. Estas nuevas perspectivas se caracterizan por deconstruir dicotomías y por la afirmación de que los diferentes tipos de racionalidades y motivaciones están siempre presentes en la acción social, y por señalar que las interacciones entre los movimientos estatales y sociales no implican necesariamente una pérdida de autonomía de los actores colectivos contestadores. En el ámbito de este artículo, se postula que si este diseño sintético permite una desviación de los supuestos normativos sobre "¿qué es la política?", es necesario que el arsenal conceptual disponible permita la comprensión de que este es un tema que está diariamente en disputa entre los diferentes actores colectivos contestatarios. Se argumenta que la contribución teórica de François Dubet ofrece una fuerte fundamentación para la construcción de un modelo apropiado para esta tarea. A partir de estas consideraciones, se propone un dislocamiento en el enfoque sociológico de la acción colectiva, abandonando la tarea de resolución teórica de los dilemas que son, de hecho, empíricos, hacia un enfoque comprensivo sobre cómo estas tensiones son resueltos por los actores involucrados de manera efectiva en acciones colectivas contestatorias. 


\section{Referências}

ABERS, R.; VON BÜLLOW, M. 2011. Movimentos Sociais na Teoria e na Prática: como estudar o ativismo através da fronteira entre Estado e sociedade?.Sociologias, 13(28):52-84.

ALONSO, A. 2009. As Teorias dos Movimentos Sociais: um balanço do debate. Lua Nova. 76: $49-86$.

. 2012. Repertório, segundo CharlesTilly: história de um conceito. Sociologia\&Antropologia,2(3):21-41.

AUYERO, J.1999. From the Client's Point(s) of View: how poor people perceive and evaluate political clientelism. Theory and Society, 28:197-334.

126.

2005. El Oficio de la Etnografia Política. Iconos Revista de CienciasSociales,22:109-

BENFORD, R.D.; SNOW, D.A. 2000. Framing Processes and Social Movements: An Overview and Assessment. Annual Review of Sociology, 26:611-639.

COHEN, J.L. 1985. Strategy or Identity: new theoretical paradigms and contemporary social movements. Social Research, 52(4):663-716.

DUBET, F. 1996.Sociologia da Experiência. Lisboa, Instituto Piaget, 282 p.

. 2007. Why remain “Classical”?European Journal of Social Theory. 10(2):247-260.

2011. La experiencia sociológica. Barcelona, Gedisa Editorial, 141 p.

Losada, $425 \mathrm{p}$.

MARTUCCELLI, D. 1999.¿En qué sociedad vivimos?Buenos Aires, Editorial

; Thaler, H. L.2004. Introduction: the sociology of collective action reconsidered. Current Sociology, 52:557-573.

FRANCIONE, G. 2007. Reflections on "Animals, Property and the Law" and "Rain Without Thunder". Law and Contemporary Problems, 70(1):9-57.

GOLDSTONE, J. A. 2003. Bridging institutionalized and noninstitutionalized politics. In: J. A. GOLDSTONE (org.),State, Parties and Social Movements. Cambridge, Cambridge University Press, p.1-24.

HANNIGAN, J.2009. SociologiaAmbiental. Petrópolis, Vozes, 270 p.

IBARRA, P. R.; KITSUSE, J. I. 1993. Vernacular Constituents of Moral Discourse: an interactionist proposal for the study of social problems. In: J. A. HOLSTEIN e G. MILLER (orgs.). Reconsidering Social Contructionism: debates in social problems theory. New Brunswick, New Jersey, Transaction Publishers, p. 25-58. 
INGRAM, H.; SCHNEIDER, A. L.; DELEON, P. 2007.Social construction and polily design.In: P. A. SABATIER (org.). Theories of the policy process. Cambridge, Westview Press, p. 93-126.

LEITÃO, L. R. S. 2012.Oportunidades Políticas e Repertórios de Ação: o movimento negro e a luta de combate à discriminação racial no Brasil. Porto Alegre, RS. Tese de Doutorado, Universidade Federal do Rio Grande do Sul - UFRGS, 152 p.

MCADAM, D. 1982.Political Process and the Development of Black Insurgency. Chicago: Universityof Chicago Press, 346 p.

MELUCCI, A. 1989. Um Objetivo para os Movimentos Sociais?.Lua Nova, 17:49-66.

. 1995. The Process of Collective Identity. In: H. JOHNSTON e B. KLANDERMANS

(orgs.),Social Movements and Culture: social movements, protest, and contention (vol.4). Minneapolis, Universityof Minnesota Press, p. 41-63.

NACONECY, C. 2009. Bem-Estar Animal ou Libertação Animal? Uma análise crítica da argumentação antibem-estarista de Gary Francione. Revista Brasileira de Direito Animal, 4(5):235-267.

NOAKES, J. A.; JOHNSTON, H. 2005. Frames of Protest: a road map to a perspective. In: H. JOHNSTON e J. A. NOAKES (orgs.), Frames of Protest: social movements and the framing perspective. Lanham, Boulder, New York, Toronto, Oxford: Rowman \& Littlefield Publishers: p.1-29.

PEREIRA, M. M. 2014. Enquadramento Interpretativo, Lógicas de Ação e Dinâmicas Interativas: dilemas em interações entre o movimento dos direitos animais e a grande mídia. Porto Alegre, RS. Dissertação de mestrado, Universidade Federal do Rio Grande do SulUFRGS, 324 p.

QUIRÓS, J. 2009. Política e Economia na Ação Coletiva: uma crítica etnográfica às premissas dicotômicas. Mana, 15(1):127-153.

SILVA, M. K. 2015. Atores, Espaços e Repertórios: a atuação de movimentos sociais através das fronteiras da sociedade civil e do Estado. In: I. SCHERER-WARREN e L. H. H. LÜCHMANN (orgs.). Movimentos Sociais e Engajamento Político: trajetórias e tendências analíticas. Florianópolis: Editora UFSC, v.1, p.133-160.

2010. De volta aos movimentos sociais? Reflexões a partir da literatura brasileira recente. Ciências Sociais Unisinos, 46(1):2-9.

; OLIVEIRA, G.L. 2011. A Face Oculta(da) dos Movimentos Sociais: trânsito institucional e intersecção Estado-Movimento - uma análise do movimento de Economia Solidária no Rio Grande do Sul. Sociologias, 13(28):86-124. 
SPERONI, T. 2012. Há outro trabalho na "outra economia”? A relação dos trabalhadores com o seu trabalho na economia solidária. Porto Alegre, RS. Dissertação de mestrado, Universidade Federal do Rio Grande do Sul - UFRGS,258 p.

STZYBEL, D. 2007. Animal Rights Law: fundamentalism versus pragmatism. Journal for Critical Animal Studies, 5(1): 1-35.

TARROW, S. 2009. O Poder em Movimento: movimentos sociais e confronto político. Petrópolis, Vozes, 319 p.

TILLY, C. 1978. From Mobilization to Revolution. New York, Random House, 337 p.

TOURAINE, A. 1989. Os Novos Conflitos Sociais. Lua Nova, 17:5-18. 1997. ¿Podremos vivir juntos? La discusión pendiente : el destino del Hombre en la Aldea Global. Buenos Aires, Fundo de Cultura Económica de Argentina, 355 p.

TRUE, J. L., JONES, B. D, BAUMGARTNER, F. R. 2007.Punctuated-Equilibrium Theory: Explaining Stability and Change in Public Policymaking, In: P. A. SABATIER (org.). Theories of the policy process. Cambridge, Westview Press, p. 155-188.

Data de recebimento: $24 / 06 / 15$

Data de aceite: 09/09/15

\section{Sobre os autores:}

Matheus Mazzilli Pereira é Bacharel em ciências sociais e mestre em sociologia pela Universidade Federal do Rio Grande do Sul. Atualmente, é doutorando em sociologia na mesma instituição de ensino e bolsista da Coordenação de Aperfeiçoamento de Pessoal de Nível Superior CAPES (Brasil). Endereço eletrônico : matheus.mazzilli@ gmail.com

Thales Speroni Pereira da Cruz é mestre em Sociologia pela Universidade Federal do Rio Grande do Sul - UFRGS (Porto Alegre, Brasil) e bolsista da Coordenação de Aperfeiçoamento de Pessoal de Nível Superior CAPES (Brasil). Atualmente é doutorando em Sociologia na UFRGS, no âmbito do grupo de pesquisa Trabalho e Reconhecimento (GTeR), e na Universidade Autônoma de Barcelona - UAB (Barcelona, Espanha), em que é vinculado ao departamento de sociologia e ao Grupo de Estudos de Imigrações e Minorias Étnicas (GEDIME). Endereço eletrônico : thalessperoni@gmail.com 